\title{
ОСОБЕННОСТИ РАБОТЫ КРИЗИСНЫХ ЦЕНТРОВ С ЖЕНЩИНАМИ, ПОСТРАДАВШИМИ ОТ СЕМЕЙНОГО НАСИЛИЯ
}

\begin{abstract}
АНнотАцИя. Анализируются проблемы семейного насилия в отношении женщин, проблемы научного поиска ответов на вопросы о том, как, каким образом и почему возникает проблема насилия внутри семьи, какова роль семейного насилия в процессах, связанных с социальными изменениями в том или ином обществе, в том числе и российском. Отмечается роль консультантов, психологов и социальных работников кризисных центров, государственных и общественных организаций, занимающихся проблемами психологической помощи и социальной адаптации жертв семейного насилия. Рассматривалась деятельность кризисных центров в отношении женщин, оказавшихся в трудной жизненной ситуации. Рассматриваются варианты әффективного осуществления предупредительной деятельности в сфере семейного насилия, необходимости не только реформирования законодательства и совершенствования практики его применения, разработки и внедрения различных форм социальной помощи жертвам и субъектам такого насилия.

кЛючЕВЫЕ сЛовА. Семейное насилие; психологическое насилие; кризисный центр; реабилитационный центр; консультант кризисного центра.

ИНФОРМАЦИЯ О СТАТЬЕ. Дата поступления 1 октября 2017 г.; дата принятия к печати 19 декабря 2017 г.; дата онлайн-размещения 29 декабря 2017 г.
\end{abstract}

T. I. Kondrya

Irkutsk National Research Technical University, Irkutsk, Russian Federation

\section{FEATURES OF CRISIS CENTER WORK WITH WOMEN AFFECTED BY DOMESTIC VIOLENCE}

\begin{abstract}
The article analyses the problems of family violence against women, the problems of scientific search for solving issues on how and why the problem of violence occurs in a family, what is the role of family violence in processes associated with social changes in a particular society, including the Russian. The article notes the role of consultants, psychologists and social workers of crisis centres, governmental and public organizations dealing with problems of psychological assistance and social adaptation of family violence victims. It considers the activity of the crisis centers in relation to women who find themselves in a difficult life situation. The author regards the options for an effective implementation of preventive activities in the sphere of family violence, the need for not only reforming the legislation and improving the practice of its application, but also developing and introducing various forms of social assistance for victims and subjects of such violence.

KEYWORDS. Family violence; psychological violence; crisis center; rehabilitation center; crisis center consultant.
\end{abstract}

ARTICLE INFO. Received October 1, 2017; accepted December 19, 2017; available online December 29, 2017.

Семейное насилие является актуальной проблемой современного российского общества. Согласно статистическим данным 30-40 \% из всех тяжких преступлений совершается в семье [1, с. 138].

Семейное насилие захватывает все социальные и культурные слои. Близкие люди, члены своей семьи, гораздо чаще, чем посторонние оказываются жертвами

\section{Baikal Research Journal}

электронный научный журнал Байкальского государственного университета 
агрессивных действий. Это относится и к ситуациям, связанным с незначительным причинением вреда здоровью или ситуациям психологического давления. Психологическое давление, к сожалению, юридически и оценочно не всегда воспринимается как ситуация насилия в отношении личности человека. Так и к более серьезным, и с юридической точки зрения, и с оценочной, преступлениям, включающим в себя, в том числе, и убийства. Именно то, что направленность агрессии против членов семьи отмечается практически во всех странах мира, позволяет обоснованно говорить об универсальности и распространённости этого явления.

Сложившаяся ситуация привлекает все больше внимание социологов, психологов, криминалистов, юристов во всем мире к выявлению причин, направленности насилия, форм проявления, характера и возможных последствий разных форм проявления насилия.

Ведется поиск ответов на вопросы о том, как, каким образом и почему возникает проблема насилия внутри семьи. Ответ на вопрос о том, какова роль семейного насилия в процессах, связанных с социальными изменениями в том или ином обществе, в том числе и российском, дает возможность бороться с этим явлением, способствовать предотвращению подобных моментов, прогнозировать влияние проблемы семейного насилия на развитие нашего общества.

Объектом научного анализа семейное насилие стало только во второй половине двадцатого века. Начиная с девяностых годов двадцатого века, проблема семейного насилия в отношении женщин находится в центре международного научного внимания.

Особенностью и специфическим аспектом данной проблемы является то, что женщины, страдающие от семейного насилия, не всегда находят защиту у общества и государства. Так как социально-правовая база для защиты их несовершенна, есть упущения и в практике ее применения и использования.

Случаи семейного насилия сложны еще и возможностью их выявления.

Недостаточно проработан вопрос фиксирования и статистического учета случаев семейного насилия в органах МВД, системе здравоохранения.

Потребность в признании существования проблемы семейного насилия, исследовании факторов, влияющих на проявление внутрисемейное насилия, и формировании ответных мер по ее разрешению, стала на сегодня несомненной и неопровержимой.

Самым тяжелым в этой ситуации является то, что домашнее насилие в отношении женщин и детей не воспринимается насилием в сознании многих людей. Кто ни слышал, что «бьет - значит, любит». Или, в оправдание мер физического воздействия на своего ребенка, «меня родители били, и, ничего, вырос человеком». Как пишет Марина Фунт в статье «Как победить семейного тирана»: «Многие считают, что они просто воспитывают детей, а не выплескивают на них агрессию, пользуясь выражением «меня в детстве били, и я нормальным вырос» [2]. Зачастую именно такие убеждения способствуют принятию и закреплению насилия в семье как некой социальной нормы.

То, что выделяют именно насилие в отношении женщин, в данном случае, не играет никакой роли, в отношении жен или сожительниц, объясняется разными причинами. Но основная та, что большая часть социологических, криминологических, юридических и медицинских исследований преступлений в бытовой среде, а также данные, которые нам дает официальная статистика и данные кризисных центров, отражают устойчивое преобладание среди потерпевших лиц женского пола в сфере насильственных преступлений, совершенных в семье.

Отдельно хочется сказать, что получившая широкое распространение такая форма совместного проживания мужчин и женщин, как сожительство, также в

\section{Baikal Research Journal}

электронный научный журнал Байкальского государственного университета 
немалой степени способствует проявлению насилия над женщиной. В данном случае, это чаще формы психологического насилия. Психологическое насилие не менее страшно, чем физическое. Да, оно не убивает сразу, как порой случается в ситуации физического насилия, но такая форма насилия - это, пусть иногда и медленное, но верное подавление самооценки, личности в человеке. Ведь не случайно, что женщин, подвергающихся психологическому насилию, психологам кризисных центров еще и убеждать приходится в том, что они стали именно жертвами. Чаще женщина убеждена в том, что сама виновата, что недопоняла, не дотерпела, не доказала, что-либо, спровоцировала, а значит, мужчина не виноват.

Многие женщины, уже пройдя курс у психолога центра, определяют подобное воздействие как самую болезненную, самую сложную для определения, сторону отношений в семье или просто с сожителем, которая порождает ощущение беспомощности, угнетенности, невозможности оказаться без бдительного сопровождения, а порой и слежки, со стороны мужчины. В значительной степени осложняет ситуацию тот факт, что данная ситуация двойственна. Мужчина вполне может быть интересным собеседником, его могут любить родственники, и не понимать, кто он и что скрывается за маской приятного, но, может быть, чуть более чем стоило бы, заботливого и внимательного мужа.

Оказавшись в подобных обстоятельствах, женщины не всегда готовы признать их. У женщин, начинают формироваться следующие личностные особенности: самоограничение, отчуждение, негативизм, отказ от выражения собственной позиции [3, с. 139].

Психологические проблемы, в свою очередь, ведут к проблемам, связанным с нарушением физического здоровья. Что дополнительно влияет на самоощущения и социальную адаптацию жертвы семейного насилия.

Перед женщинами, пытающимися найти выход в ситуации семейного насилия, нередко, встают материальные, жилищные, юридические проблемы.

Проблема принятия их поступка в семьях и близком окружении. Не секрет, что часто женщину пытаются остановить доводами такого рода, как: «он не хуже других. Деньги хотя бы приносит», «Не позорь семью. Не хватало нам только развода», «Кому ты будешь нужна со своими детьми?» и иные доводы, но того же толка.

Собственно, вот и возникает вопрос о необходимости создания специальных организаций, деятельность которых будет направлена на решение проблем, рассматриваемой нами категорий женщин.

В условиях деятельности организаций социальной помощи, кризисных центров, центров психологической помощи и иных подобного рода организаций, встает вопрос квалификации кадров. $К$ сожалению, достаточно часто, работающие социальные работники таких центров, консультанты, сотрудники, отвечающие на вызовы телефона доверия, нередко не имеют психологического образования, образования социального работника, а значит и профессиональных, практических навыков работы с клиентами кризисных центров, что, несомненно, снижает качество оказываемой ими психологической помощи.

Таким образом, возникает потребность и в квалифицированных специалистах разной профессиональной направленности. В социальных работниках, психологах, сотрудниках кризисных центров и иных организаций, помогающих жертвам насилия. В тех, кто способен оказать эффективную и грамотную, психологическую и юридическую помощь такой категории клиентов, как жертвы семейного насилия.

В современной России, как и во всем мире, развивается система социальных служб - кризисных центров, специализирующихся на оказании помощи жертвам семейного насилия. Кроме государственных организаций с подобной категорией клиентов работают и негосударственные некоммерческие организации.

\section{Baikal Research Journal}

электронный научный журнал Байкальского государственного университета 
Важно отметить, что социально-ориентированные некоммерческие организации - это организации, деятельность которых направлена, в первую очередь, на решение социальных проблем общества в целом.

Например, такие, как центр помощи гражданам, пострадавшим от семейного насилия «Мария» (АНО «ИРЦСПП» «Мария»). Авторы иркутского проекта предлагают создать реабилитационный центр, в котором женщина смогла бы находиться столько времени, сколько ей потребуется для того, чтобы встать на ноги и обрести точку опоры в жизни [2].

Деятельность кризисных центров определяется как деятельность учреждений социального обслуживания, направленных на оказание помощи и социальной реабилитации лиц, подвергшихся любой форме семейного насилия. Также помощи тем своим клиентам, которые в такой ситуации потеряли жилье или работу, оказались в экстремальной, кризисной бытовой или социальной ситуации $[4$, с. 358$]$.

В этой связи, представляется интересным и даже необходимым рассмотреть деятельность такого рода центров и социально-ориентированные некоммерческие организаций в разных обществах.

Например, Германия. Отдельно нужно будет рассматривать ситуации насилия в семьях, где оба супруга имеют гражданство, отдельно, где муж имеет немецкое гражданство, а жена - ограниченный вид на жительство.

Чаще всего проявление домашнего насилия происходит в семьях, где жена не имеет гражданства. Именно в таких семьях, происходят случаи насилия. И при этом, женщины долго молчат о происходящем в их семья. Это связано и с тем, что женщины боятся быть высланными из страны и иметь проблемы юридического характера, и с тем, что потеряют себя в глазах родственников, оставшихся в прежней стране проживания. Кроме того, они просто не уверены в том, что законы Германии не будут на их стороне. И напрасно. В Германии действует закон «О судебных мерах по защите жертв от насилия и преследования», который предусматривает защиту жертвы, если в отношении неё предпринимается насилие в виде нанесения телесных повреждений, ограничения в правах и т.п.

Закон предусматривает защиту жертвы от насилия и преследования в виде запрета нарушителю домашнего спокойствия появляться в квартире на определённый срок (не зависимо от того, кто является собственником этой квартиры); запрещает приближаться к жертве на определённое расстояние, преследовать её, звонить по телефону, слать СМС, даже через третьих лиц [5].

Здесь видится одна, но очень значимая проблема. Неинформированность потенциальных жертв о своих правах, о законах их защищающих, об организациях, готовых оказать им помощь. Эта проблема является значимой и для России.

Канада, Австрия, и Швеция считаются признанными и заслуженными лидерами в деятельности, направленной на разработку и проведении политики противодействия насилию в семье [6, с. 15$]$.

Важно, что власти и общественные организации стремятся учитывать потребности групп населения со специальными нуждами: женщин-инвалидов, аборигенок, представительниц национальных меньшинств [7, с. 109]. Основы этой системы определены в Австрийском Федеральном Акте по защите от домашнего насилия.

В Австрии действует сеть центров интервенции (вмешательства), которые осуществляют координацию действий полиции и социальных служб и реализуют активный подход к помощи пострадавшим [7].

Центры финансируются Министерством внутренних дел и Министерством по делам женщин, но управляются женскими неправительственными организациями $[8$, с. 154].

\section{Baikal Research Journal}

электронный научный журнал Байкальского государственного университета 
Основными задачами Центра интервенции являются оценка опасности в случаях домашнего насилия; оказание поддержки и помощи в планировании безопасности пострадавшей и любых зависимых от нее лиц; юридическое консультирование жертв насилия в семье и поддержка их в государственных органах и судах; содействие в социальном обустройстве жертв насилия, их психологической и медицинской реабилитации; предоставление фактического убежища женщинам, детям [9, с. 18].

Беларусь, совместно с Великобританией, Швецией и Фондом ООН, реализует проект по противодействию гендерному насилию (в частности, насилию в семье). Он рассчитан на 2016-2018 годы и предусматривает совершенствование законодательства в области противодействия домашнему насилию, работу с мужчинами-агрессорами и улучшение социальной защиты пострадавших женщин ${ }^{1}$.

В качестве одной из значимых мер противодействия в разных странах, в том числе и России, рассматривается действия бесплатной телефонной линии. Своя служба, круглосуточный телефон доверия, действует и в Иркутске.

Жћителям Ангарска можно обратиться за помощью к сотрудникам Благотворительного фонда «Семьи - детям» .

Благотворительный фонд помощи нуждающимся «Спаси и сохрани» помогает в трудных ситуациях. В том числе в ситуации семейного насилия. Сотрудниками фонда также проводится индивидуальная работа с женщинами, планирующими совершить аборт.

Интересен опыт деятельности Ассоциации общественных объединений многодетных семей Иркутской области «Берегиня» .

Помощь в составлении жалоб, заявлений, и других документов правового характера женщины, оказавшиеся в трудной жизненной ситуации, могут получить в ФГУ «Государственное юридическое бюро по Иркутской области», а также бесплатно в любой адвокатской коллегии Иркутска.

Одним из направлений деятельности ОГБУСО «Территориальный центр социальной помощи семье и детям», является выявление, профилактика и работа со случаями жестокого обращения с несовершеннолетними. Также экстренная психологическая помощь детям, в том числе и по телефону.

Телефон доверия экстренной психологической и психотерапевтической помощи действует в городе Иркутске круглосуточно. Также как и телефон доверия МВД. Имеется своя «горячая» линия и в Психологической службе поддержки беременных женщин, находящихся в трудной жизненной ситуации. Здесь помощь оказывают социальный работник и психолог.

Цель телефонного контакта - выслушать, понять проблему, поддержать, определить вид необходимой помощи и организовать, если надо, консультацию. Кроме того, именно в таком, иногда первом, телефонном разговоре, сотрудник центра имеет возможность получить подробные сведения о месте и режиме работы специалистов и другие необходимые данные.

Линия доверия имеет большое эмоциональное значение для женщин подвергшимся насилию или детей, которым, в большинстве случаев, непонятно кому некому довериться, раскрыться, признаться, а в данном виде поддержки анонимность является решающим фактором.

Основные причины стрессовых (кризисных) ситуаций для женщин, обращающихся на линию доверия, определяются следующие: домашнее насилие против женщин и детей; изнасилование; внутрисемейные отношения (конфликты между супругами); безработица или угроза потери работы; ухудшение состояния

1 «Сформировать нетерпимое отношение». В Беларуси начат проект о противодействии насилию в семье // News.21.BY. Минск, 2017. URL: http://news.21.by/society/2016/12/01/1269038.html.

\section{Baikal Research Journal}

электронный научный журнал Байкальского государственного университета 
физического и психического здоровья женщины или детей; конфликты между родителями и детьми; юридические проблемы; конфликты на работе, в трудовом коллективе; уход из жизни близких людей [4, с. 358].

Проблема в том, что женщины или дети, чаще всего оказывающиеся жертвами семейного насилия или трудной жизненной ситуации, просто не информированы о деятельности всех организаций, готовых оказать им помощь.

Первый в России кризисный центр для женщин был организован на базе «горячей линии» для женщин, подвергшихся насилию в 1993 году.

Этот центр работал по трем направлениям: оказывал реальную помощь конкретным женщинам, разрабатывал некоторую модель кризисного центра, которая потом постепенно распространилась по всей территории страны, а также центр являлся полигоном научного исследования, базой накопления необходимой для этого информации.

Развитие кризисных центров как неприбыльных социальных организаций привело к образованию Ассоциации кризисных центров в 1999, которая стала оказывать методическую и организационную помощь новым формированиям.

Наряду с этой общественной системой активно выступили и государственные органы, реализовавшие большую программу по созданию центров семейной помощи, естественным образом включавших и функции преодоления домашнего насилия [10, с. 9].

Первые кризисные центра были созданы как результат инициативы и деятельности различных неправительственных женских организаций. Центры создавались как организации, оказывающие квалифицированную помощь таких специалистов, как психологи, медики, юристы. Человек, ставший жертвой семейного насилия, придя в такой кризисный центр, может быть уверен, что его выслушают с позиции уважения и принятия, что не будут давать оценку его поведению.

Цель создания таких центров - оказание психологической, юридической, педагогической, социальной и других видов помощи женщинам, находящимся в кризисном и опасном для физического и душевного здоровья состоянии или подвергшимся психофизическому насилию.

Представляется, что главными задачами деятельности кризисных центров являются те направления работы, которые способствуют созданию необходимых условий для социально-психологической реабилитации и адаптации женщины в обществе и семье.

К числу тех, кто имеет право на получении помощи в кризисном центре, относятся следующие лица: подвергшиеся психологическому и физическому насилию, те, кто потерял родных и близких; потерявшие родных и близких (вдовы); имеющие детей-инвалидов; женщины-инвалиды;

беременные женщины, в том числе несовершеннолетние и одинокие; находящиеся в конфликте с семьей; находящиеся в отпуске по уходу за ребенком; беременные женщины, в том числе несовершеннолетние и одинокие; самостоятельно проживающие выпускницы детских домов и школ-интернатов; девочки-подростки, оказавшиеся в трудной жизненной ситуации.

Еще одной из форм работы кризисного центра является очное консультирование. В этом случае общаются непосредственно со специалистами в конкретной области.

Как правило, помощь, оказывается, по таким направлениям как: социально-психологическая поддержка. Она необходима для прояснения жизненной ситуации, в которой оказался клиент кризисного центра; психотерапевтическая помощь; помощь, в случае депрессии. Такая помощь имеет психологический, а не медикаментозный аспект; юридические консультации по текущему законодательству; группы поддержки и другие формы помощи.

\section{Baikal Research Journal}

электронный научный журнал Байкальского государственного университета 
Главной задачей первого встречи или первого телефонного разговора, как уже было отмечено, является задача снять психологическое напряжение, оказать, если необходимо, срочную юридическую помощь. При этом задача социального работника - выслушать клиентку, понять ее проблему, поддержать, определить вид реальной помощи, а при необходимости направить на консультацию.

Такая форма общения для женщин важна, прежде всего, эмоционально, так как она часто изолирована и оказывается один на один с обострившимися житейскими проблемами.

Следует иметь в виду, что обратившаяся в Кризисный центр женщина находится в противоречивом состоянии: с одной стороны, российский менталитет не позволяет «выносить сор из избы», а с другой - она уже не может сдерживать отрицательные эмоции [4, с. 360]. Однако эмоции - это только поверхность проблемы. Для решения проблемы требуется помощь соответствующей квалификации и необходимо направить женщину на консультацию к специалисту.

Главные виды консультаций: психотерапевтическая - немедикаментозная форма помощи в случае депрессии, страхов, возбуждения. Юридическая - консультации по текущему законодательству в области прав и гарантий женщинам и детям, включая вопросы брака и развода, получения алиментов и пособий, льгот женщинам на производстве. Экономическая - связана с трудоустройством, а также со всеми направлениями переквалификации. Сюда же относятся вопросы изменения вида деятельности с целью организации малого бизнеса, семейного предприятия, надомного труда. Жилищная - различные аспекты проблемы жилищной обеспеченности, обостряющейся при разводе, приватизации жилья. Медицинская - чаще всего связана с гинекологической помощью по методам планирования семьи или в случае бесплодия. Социально-психологическая - направлена на прояснение возникшей жизненной ситуации, прежде всего для самой женщины.

Обращение женщины должно фиксироваться в документах Центра. Это либо это небольшая анкета, либо это книга регистрации. Возможны оба способа. Строго сохраняется анонимность. Как правило, первичный контакт потерпевшей со специалистами бывает длительным и сама процедура его имеет особое психологическое значение [4, с. 361].

В условиях кризисного центра при оказании социальных услуг женщинам, пострадавшим от семейного насилия, специалисты реализуют как общие, так и специальные принципы социальной работы. Общими принципами являются принцип гуманизма, принцип законности, принцип социальной справедливости, принцип эффективности и принцип профессионализма.

В Иркутске на данный момент существует два кризисных центра, оказывающих помощь женщинам и девушкам, перенесшим насилие. Это Иркутская региональная общественная некоммерческая организация «Кризисный Центр для Женщин» и Кризисный центр «Мария» .

Иркутская региональная общественная некоммерческая организация «Кризисный Центр для Женщин» существует в городе Иркутске с 1995 года. Она является одним из первых центров и входит в Национальную сеть кризисных центров России.

До 1998 года Иркутский Центр был единственным от Урала до Дальнего Востока. С 1998 на протяжении 5 лет сотрудниками Центра реализовывался проект «Организация сети Кризисных центров региона Сибири и Дальнего Востока. В настоящее время работает как Ресурсный Центр для Иркутской области.

Его сотрудниками были созданы первые методические пособия по организации помощи семье находящейся в ситуации насилия.

\section{Baikal Research Journal}

электронный научный журнал Байкальского государственного университета 
Данный кризисный центр специализируется на психологической помощи женщинам. В центре можно получить помощь по телефону доверия, в виде очного консультирование и в группе поддержке.

По телефону доверия «Кризисного Центра для ЖЖенщин» осуществляется первая психологическая помощь.

Как уже было сказано выше, главная задача данного вида помощи - это предупреждение и блокирование кризисов. Или направить тех, кто обратился за помощью к службам, способным оказать более полную, более квалифицированную помощь.

В Иркутском «Кризисном Центре для Женщин» оказывают психологическое сопровождение лиц, переживших семейное насилие, осуществляется в двух основных направлениях: экстренная психологическая помощь при острой травме и посттравматическом стрессе; длительное сопровождение в процессе индивидуального консультирования и групповой работы.

Действует группа психологической помощи. В таких группах каждый из участников встречи может рассказать о своей проблеме, получить эмоциональную поддержку в процессе общения, высказать свои мысли и поделиться своим жизненным опытом выхода из кризисной ситуации. Психологи помогают анализировать проблему конкретного участника группы, проблему, являющуюся общей, для некоторых из участников, или, например, провести анализ на примере из практики консультирования

Кризисный центр «Мария» начал свою волонтерскую деятельность в июле 2011 года. К основным целям кризисного центра относятся: профилактика социального сиротства, своевременная психологическая помощь и поддержка несовершеннолетних; оказание комплексной поддержки женщинам, оказавшимся в трудной жизненной ситуации, а также одиноким матерям, воспитывающим несовершеннолетних детей, и беременным женщинам (в том числе несовершеннолетним и одиноким), находящимся в кризисной ситуации.

Формы помощи женщинам, пострадавшим от семейного насилия, оказываемые в центре: юридическая помощь; психологическая помощь; временный приют; материальная помощь (в ограниченном количестве); помощь в трудоустройстве.

Методы реабилитации, который предоставляет Центр это индивидуальная и групповая терапии. Чаще всего групповая терапия. Но не все женщины, особенно, пострадавшие от насилия, соглашаются на групповые сеансы. Для таких женщин предусмотрены иные формы реабилитации.

Один раз в неделю проводятся тренинги. Психологический тренинг является хорошим дополнением к психологическому консультированию и может быть использован либо вместо психотерапии (при не слишком глубинных проблемах), либо параллельно с психотерапией. Тренинг по снятию психоэмоционального напряжения направлен на гармонизацию эмоционального состояния, снижение эмоционального напряжения и тревоги, а также на восстановление жизненных сил. Тренинг по развитию эмоциональной связи между матерью и ребенком.

Поскольку многие из женщин, подвергшихся домашнему насилию, воспроизводят схему насилия в своих взаимодействиях с детьми, становится актуальными применение тренингов детско-родительских отношений. Также проводятся тренинги по социально-психологической адаптации и по вопросам поддержания здорового образа жизни. Помимо всего прочего проводятся беседы и консультации с семьей пострадавшей, психологическая помощь мужчинам, желающим сохранить семью.

Кризисный центр «Мария» организует различные проекты. В первую очередь это проект создания убежищ «Новый путь». Основой этого проекта стало то, что

\section{Baikal Research Journal}

электронный научный журнал Байкальского государственного университета 
в 2015 году кризисному центру было передано помещение и участок земли в Иркутском районе.

C 2016 года постоянно действует проект «Доступный юрист». Центр, совместно с региональной общественной приемной Д. Медведева, юристом кризисного центра и руководителем АНО «ИРЦСПП» Кризисный Центр «Мария», проводит два раза в месяц бесплатные консультации юриста для женщин, с последующим сопровождением, если ситуация того требует. С 2015 года и по настоящее время работает проект «Дом добрых дел» [11, с. 77].

Таким образом, можно сделать вывод, что вся деятельность специалистов кризисных центров направлена, в первую очередь, на устранение последствий уже свершившегося акта семейного насилия. Также на работу с женщинами, решившимися на развод после ситуации семейного насилия. И эта очень важная часть их деятельности. Поскольку, в большинстве случаев, необходима не только помощь юриста, но и помощь сотрудника, направленная на поддержку женщины, принявшей такое непростое для нее решение. В современном обществе большинством все так же не принимаются женщины, решившиеся на развод. Даже если он спасает ей жизнь. Общепринятые стереотипы, что женщина должна быть терпеливой, сохранять семью, во что бы то ни стало, что стыдно быть не замужем или разведенной, мешают женщине быть свободной в принятии решений.

Но, к сожалению, деятельность специалистов, направленна на работу с жителями города по профилактике насилия в семье, на сегодняшний момент, неудовлетворительна. Ее объемы незначительны. Достаточно сказать, что даже, порой таких жизненно важных телефонов, как телефон служб доверия, женщины просто не знают.

Таким образом, специалистам центра можно рекомендовать проводить больше просветительской работы с населением для того, чтобы жители города получили представление о кризисном центре для женщин. Кроме того, необходимо приложить усилия для того, чтобы тема семейного насилия и его последствий, стала больше освещаться региональными СМИ.

Также, в деятельности центров, больше внимания следует уделять виктимологической профилактике, поскольку такая информация должна обращать внимание женщин на опасность вступления в брак с человеком, склонным к насилию, властным, эмоционально неуравновешенным, злоупотребляющим спиртными напитками или ущемляющим права женщины.

Необходимо проведение различных тренингов и семинаров для женщин, направленных на обучение распознавать признаки совершаемого в отношении них насилия и разъяснять все возможные негативные.

Дополнительно следует распространять информацию о существующих видах помощи жертвам семейного насилия и необходимости получения такой помощи для защиты своих прав и прохождения курса психологической реабилитации.

В деятельности специалистов кризисных центров и иных организаций, необходимо учитывать, что причины, по которым женщины не могут или не пытаются разорвать отношения с теми, кто является подчас угрозой даже для их жизни, могут быть различны. Это и просто страх. И отсутствие реальных альтернатив трудоустройства и финансовой помощи, особенно для жертв с детьми. Кроме того, отсутствие жилья, куда можно уйти или где можно остаться без семейного насильника. А также культурные и семейные ценности, призывающие к сохранению семьи любой ценой. Влияние окружения. Того окружения, которое убеждает жертву, что она сама виновата в насилии и что она может остановить его, подчинившись требованиям партнера. В данной ситуации жертве необходима помощь.

Помощь же центрам может прийти и от комитета по здравоохранению и социальной защите Законодательного собрания Иркутской области. А также от

\section{Baikal Research Journal}

электронный научный журнал Байкальского государственного университета 
бизнеса, в рамках частного и государственного партнерства. Также, центрам необходимо принимать участие в конкурсах и грантах, для того, чтобы появилась возможность участия в региональных программах. И, в первую очередь, необходимо совершенствовать просветительскую деятельность кризисных центров.

Кроме того, практическая деятельность консультанта кризисного центра связана со значительными психологическими нагрузками, а значит и является необходимой организация системы контроля психологических состояний консультанта, решение проблемы профессионального стресса, психологического выгорания. Это необходимо делать с целью соответствующего выявления нарушений и последующей коррекции состояния психолога, социального работника, консультанта организации.

Помимо уже выделенных аспектов, выявляется значимость и перспектива изучения психологических особенностей жертв насилия, форм и методов практической работы с такими людыми.

Одним словом, появление кризисных центров для женщин играет важную роль, гарантируя женщинам безопасность и разные виды краткосрочной поддержки.

Поэтому для эффективного осуществления предупредительной деятельности в сфере семейного насилия необходимо не только реформирование законодательства и совершенствование практики его применения, но и разработка и внедрение различных форм социальной помощи жертвам и субъектам такого насилия.

При исследовании проблемы семейного насилия необходимо учитывать и то, что особенность данной проблемы, заключается в том, что она затрагивает самую закрытую от общества сторону жизни человека. Ведь на семью, влияют не только нормы современного права, но и сложившиеся социальные нормы, традиции, религиозное влияние и стереотипность восприятия, а точнее, отсутствие восприятия семейного насилия над женщиной, как негативного социального явления.

Сложность проблемы домашнего насилия говорит о необходимости комплексной помощи, главными целями которой являются: предотвращение семейного насилия над женщинами, защита с целью обеспечения безопасности женщин и обеспечение профессиональной помощи и консультирования.

\section{Список использованной литературы}

1. Жигунова Г. В. Причины насилия над женщинами в семье / Г. В. Жигунова, Н. О. Пономаренко // Известия высших учебных заведений. Поволжский регион. Общественные науки. - 2015. - № 2 (34). - С. 137-144.

2. Фунт М. Как победить семейного тирана [Электронный ресурс] / М. Фунт // MК Байкал : poc. регион. еженедельник. - Иркутск, 2017. - Режим доступа: http://baikal. mk.ru/articles/2013/03/19/827778-kak-pobedit-semeynogo-tirana.html.

3. Сошникова И. В. Насилие - социальная опасность семьи / И. В. Сошникова, В. И. Шерпаев // Известия УрГЭУ. - 2012. — № 5 (43). - С. 137-141.

4. Кризисные центры как система социальной поддержки населения / Е. А. Брачкова [и др.] // NovaInfo.Ru. - 2016. - T. 1, № 47. - C. 358-361.

5. Энгельман И. Домашнее насилие или насилие в семье [Электронный ресурс] / И. Энгельман. - Режим доступа: https://olesan2011.wordpress.com/2012/03/23.

6. Забелина Т. Ю. Канада и проблема насилия в семье: двадцать лет борьбы / Т. Ю. Забелина, Е. В. Исраелян, Н. А. Шведова // Вопросы ювенальной юстиции. 2006. - № 4. - С. 15-18.

7. Заброда Д. Г. Австрийский опыт предупреждения домашнего насилия: характеристика и предложения по использованию в России / Д. Г. Заброда, С. Н. Заброда // Общество и право. - 2016. - № 3 (57). - С. 107-112.

8. Принося безопасность домой: борьба с насилием в отношении женщин в регионе ОБСЕ. Сборник примеров хорошего опыта : публ. Секретариата ОБСЕ / под ред. Дж. Сефтауи. Вена, 2009. - 156 c.

\section{Baikal Research Journal}

электронный научный журнал Байкальского государственного университета 
9. Джирарди Дж. Обзор международного опыта и передовой практики противодействия домашнему насилию в 5 странах (Австрия, Украина, Великобритания, Израиль, Казахстан) / Дж. Джирарди ; Трастовый фонд ООН «Остановить насилие в отношении женщин». - 2-е изд., испр. - [Б. м. : б. и.], 2012. - 34 с.

10. Тугайбаева Б. Н. Кризисные центры и «социальный адвокат» / Б. Н. Тугайбаева // Информационно-аналитический бюллетень. - 2001. - № 20 (50). — С. 9-10.

11. Черствая О. Е. Современное состояние деятельности российских некоммерческих организаций по сопровождению женщин / О. Е. Черствая // Проблемы развития территории. - 2012. - № 3 (59). - С. 76-83.

\section{References}

1. Zhigunova G. V., Ponomarenko N. O. Social Factors of Violence against Women in Families. Izvestiya vysshikh uchebnykh zavedenii. Povolzhskii region. Obshchestvennye nauki= Univesity proceedings. Volga region. Social sciences, 2015, no. 2 (34), pp. 137-144. (In Russian).

2. Funt M. How to defeat a family tyrant. Available at: http://baikal.mk.ru/ articles/2013/03/19/827778-kak-pobedit-semeynogo-tirana.html. (In Russian).

3. Soshnikova I. V., Sherpaev V. I. Violence is a social danger for family. Izvestiya Ural'skogo gosudarstvennogo ekonomicheskogo universitetata = Journal of the Ural State University of Economics, 2012, no. 5 (43), pp. 137-141. (In Russian).

4. Brachkova E. A., Dergunova I. V., Dorovskikh A. S., Zhabina A. V. Crisis centres as a system of public social support. NovaInfo.Ru, 2016, vol. 1, no. 47, pp. 358-361. (In Russian).

5. Engelman I. Domestic violence or family violence. Available at: https://olesan2011. wordpress.com/2012/03/23. (In Russian).

6. Zabelina T. Yu., Israelyan E. V., Shvedova N. A. Canada and problem of domestic violence: twenty years of struggle. Voprosy yuvenal'noi yustitsii = Issues of Juvenile Justice, 2006, no. 4, pp. 15-18. (In Russian).

7. Zabroda D. G., Zabroda S. N. Austrian Experience to Prevent Home Violence: Characteristics and Suggestions to Employ in Russia. Obshchestvo i pravo = Society and Law, 2016, no. 3 (57), pp. 107-112. (In Russian).

8. Seftaui Dzh. (ed.). Prinosya bezopasnost' domoi: bor'ba s nasiliem $v$ otnoshenii zhenshchin $v$ regione OBSE. Sbornik primerov khoroshego opyta [Bringing security home: struggle against violence in regard of women in the OSCE region. Collection of good experience examples]. Vienna, 2009. $156 \mathrm{p}$.

9. Dzhirardi Dzh. Obzor mezhdunarodnogo opyta i peredovoi praktiki protivodeistviya domashnemu nasiliyu $v 5$ stranakh (Avstriya, Ukraina, Velikobritaniya, Izrail', Kazakhstan) [Review of international experience and progressive practice of counteracting to domestic violence in five countries (Austria, Ukraine, UK, Israel, Kazakhstan]. $2^{\text {nd }}$ ed. 2012. 34 p.

10. Tugaibaeva B. N. Crisis centres and «social lawyer». Informatsionno-analiticheskii byulleten' = Information-Analytic Bulletin, 2001, no. 20 (50), pp. 9-10. (In Russian).

11. Cherstvaya O. E. Current State of Russian Non-Profit Organizations Aimed at Women Support. Problemy razvitiya territorii $=$ Problems of territory's development, 2012, no. 3 (59), pp. 76-83. (In Russian).

\section{Информация об авторе}

Кондря Татьяна Ивановна - кандидат социологических наук, доцент, кафедра социологии и психологии, институт экономики, управления и права, Иркутский Национальный Исследовательский Технический Университет, 664074, г. Иркутск, ул. Игошина, 4, email: tata.irk.1970@yandex.ru.

\section{Author}

Tatiana I. Kondrya - PhD in Sociology, Associate Professor, Chair of Sociology and Psychology, Irkutsk National Research Technical University, 4 Igoshin St., 664074, Irkutsk; email: tata.irk.1970@yandex.ru.

\section{Baikal Research Journal}




\section{Для цитирования}

Кондря Т. И. Особенности работы кризисных центров с женщинами, пострадавшими от семейного насилия / Т.И. Кондря // Baikal Research Journal. - 2017. — Т. 8, № 4. — DOI : 10.17150/2411-6262.2017.8(4).7.

\section{For Citation}

Kondrya T. I. Features of crisis center work with women affected by domestic violence. Baikal Research Journal, 2017, vol. 8, no. 4. DOI: 10.17150/2411-6262.2017.8(4).7. (In Russian).

\section{Baikal Research Journal}

